\title{
RepSox effectively promotes the induced differentiation of sheep fibroblasts into adipocytes via the inhibition of the TGF-ß1/Smad pathway
}

\author{
YU GUO $^{1 *}$, HUAN ZHU ${ }^{1 *}$, XIANGCHEN LI ${ }^{2,3^{*}}$, CAIYUN MA $^{1,2}$, YANAN LI $^{2}$, TINGTING SUN ${ }^{1}$, \\ YUANYUAN WANG ${ }^{1}$, CHUNJING WANG $^{1}$, WEIJUN GUAN ${ }^{2}$ and CHANGQING LIU ${ }^{1}$ \\ ${ }^{1}$ Department of Laboratory Medicine, School of Life Sciences, Bengbu Medical College, Bengbu, Anhui 233000;
${ }^{2}$ Institute of Beijing Animal Science, Chinese Academy of Agricultural Sciences, Beijing 100193; ${ }^{3}$ College of
Animal Science and Technology, Zhejiang A\&F University, Hangzhou, Zhejiang 311300, P.R. China
}

Received August 24, 2020; Accepted May 10, 2021

DOI: $10.3892 /$ ijmm.2021.4981

\begin{abstract}
Previous reports have demonstrated that RepSox can function as a replacement for $\mathrm{cMyc}$ and Sox 2 in the reprogramming of cells into induced pluripotent stem cells (iPSCs), as well as increasing the levels of bone morphogenetic protein (BMP)-3 and inducing the phosphorylation of Smad1 in mouse embryonic stem cells. In the present study, it was demonstrated that RepSox caused the visible morphological transformation of sheep fibroblasts; however, no significant alterations in cell proliferation, apoptosis or chromosome aberrations were observed. Moreover, RepSox increased the plasticity of long-term cryopreserved sheep fibroblasts, and further promoted differentiation into adipocytes. RepSox treatment led to a notable decrease in the expression of components of the transforming growth factor (TGF) $-\beta$ signaling pathway, particularly Smad2/3 phosphorylation. RepSox also activated the BMP pathway, promoted the reprogramming of cells from fibroblasts into adipocytes and induced mesenchymal-epithelial transition. It is worth noting that RepSox notably increased the expression of octamer-binding transcription factor 4 and L-Myc, whereas Sox 2 and Nanog expression were not detected. The results of high-throughput RNA sequencing revealed that the levels of differentially expressed genes (DEGs) involved
\end{abstract}

Correspondence to: Dr Changqing Liu, Department of Laboratory Medicine, School of Life Sciences, Bengbu Medical College, 2600 Donghai Avenue, Bengbu, Anhui 233000, P.R. China

E-mail: lcq7813@bbmc.edu.cn

Dr Weijun Guan, Institute of Beijing Animal Science, Chinese Academy of Agricultural Sciences, 2 Yuanmingyuan West Road, Beijing 100193, P.R. China

E-mail:wjguan86@hotmail.com

*Contributed equally

Key words: RepSox, adipogenic differentiation, fibroblasts, octamer-binding transcription factor 4, transforming growth factor- $\beta /$ Smad in various metabolic processes were markedly upregulated in the RepSox-treated fibroblasts, while the DEGs in the majority of signaling pathways were markedly downregulated. On the whole, the present study demonstrates that RepSox can promote the plasticity of sheep fibroblasts and facilitates the differentiation of adipocytes via increasing BMP expression and inhibiting the activation of the TGF- $\beta$ signaling pathway.

\section{Introduction}

Recent research has demonstrated that fibroblasts can be reprogrammed into different cell types by altering gene expression regulation, and can even be induced to differentiate into terminal cell types, including neurons, cardiac cells and macrophage-like cells $(1,2)$. Induced pluripotent stem cells (iPSCs) can be successfully produced by reprogramming embryonic or adult somatic cells with four pluripotent transcription factors (3). However, the slow reprogramming process, low rearrangement efficiency, reprogramming inconsistency and the potential oncogenic hazards, limit the clinical applications of iPSCs (4). Currently, some small molecules can be used to reduce the risk and improve reprogramming efficiency, and produce unmodified iPSC lines with improved suitability for downstream applications $(5,6)$.

The transforming growth factor (TGF)- $\beta$ superfamily plays an important role in a variety of pathophysiological processes, as well as in regulating cellular responses, including differentiation, proliferation, growth, adhesion, migration, survival and the specification of developmental fate (7). RepSox, a selective inhibitor of the TGF- $\beta$-RI/ALK5 pathway, has been used to replace cMyc and Sox 2 during cellular reprogramming of murine embryonic fibroblasts into iPSCs (8). Moreover, RepSox can attenuate skin fibrosis (9), improve the developmental potential of somatic cell nuclear transfer embryos (10-12), and promote the development of leukemic stem/progenitor cells (13). RepSox has been demonstrated to effectively block the phosphorylation of Smads by inhibiting the TGF- $\beta$ signaling pathway, and this inhibition may contribute to a more efficient induction of iPSCs $(14,15)$. 
Bone morphogenetic proteins (BMPs) are members of the TGF- $\beta$ superfamily, and have multiple functions in promoting the differentiation of pluripotent stem cells into adipocytes, osteoblasts, chondrocytes and muscle cells (16). Recent studies have confirmed that human adipose tissue is an important means of energy storage, showing important features in energy metabolism, immune function and blood glucose regulation $(17,18)$. However, to the best of our knowledge, at present, there is no report available on the direct differentiation of sheep fibroblasts into adipocytes induced by small molecule compounds. Given the importance of TGF- $\beta$ in adipogenesis and the potential application of RepSox in clinical medicine (19), the present study aimed to evaluate the effects of RepSox on adipogenesis in adult sheep fibroblasts, and analyzed the changes in biological characteristics during the process of directed differentiation.

\section{Materials and methods}

Cell recovery and culture of Mongolian sheep fibroblasts. A male adult Mongolian sheep was provided by the Animal Experimental Base of Institute of Beijing Animal Science and Veterinary, Chinese Academy of Agricultural Sciences. The use of animals and all experimental procedures were approved by Institutional Animal Care and Use Committee (IACUC) for Ethics of Bengbu Medical College (approval no. 2017-016). Following local anesthesia with $0.5 \mathrm{ml} 2 \%$ lidocaine hydrochloride subcutaneously, the ear edge tissue of Mongolian sheep was obtained using an ear puncher for fibroblast culture.

The Mongolian sheep adult fibroblasts (SAFs) were cultured using the tissue adherent culturing method and enzyme digestion, and cryopreserved for $>10$ years in liquid nitrogen. To recover the cells, the frozen vials were removed from the liquid nitrogen and rapidly thawed in a water bath at $42^{\circ} \mathrm{C}$, following which they were transferred into a flask in DMEM (Gibco; Thermo Fisher Scientific, Inc.) supplemented with 10\% FBS (Gibco; Thermo Fisher Scientific, Inc.) and incubated at $37^{\circ} \mathrm{C}$ in a $5 \% \mathrm{CO}_{2}$ atmosphere.

Effects of RepSox on cell proliferation, apoptosis and cell cycle. RepSox (cat. no. R0158-25MG) was purchased from Sigma-Aldrich; Merck KGaA and dissolved in DMSO solution. The SAFs (below passage 6) in the logarithmic phase were treated with RepSox $(10,15,20$ and $25 \mu \mathrm{M})$ for four days. Negative control cultures were maintained in the same volume of DMSO without RepSox. After fixing with $4 \%$ paraformaldehyde for $18 \mathrm{~min}$, permeabilization with $0.1 \%$ Triton X-100 (v/v) for $10 \mathrm{~min}$ and blocking with $1 \%$ bovine serum albumin (BSA, w/v, Sigma-Aldrich; Merck KGaA) for $1 \mathrm{~h}$ at room temperature, the effect of RepSox on the cell actin cytoskeleton was detected using Alexa Fluor 568 phalloidin labeling staining (1:200; cat. no. A12380; Invitrogen; Thermo Fisher Scientific, Inc.). Cell proliferation was detected via immunofluorescence using a monoclonal antibody against BrdU (1:200; Cell Signaling Technology, Inc.) for $2 \mathrm{~h}$ at room temperature and incubation with Alexa Fluor 546-labeled secondary antibody (1:500; cat. no. A10036; Invitrogen; Thermo Fisher Scientific, Inc.) for $1 \mathrm{~h}$ at $37^{\circ} \mathrm{C}$, after cell fixation and blocking at room temperature $(20,21)$. The results of the immunofluorescence staining were observed under a fluorescence microscope (IX71, Olympus, Inc.).
Cells were harvested, and fixed with $70 \%$ ethanol at $-20^{\circ} \mathrm{C}$ overnight. The cells were then stained with propidium iodide $(50 \mu \mathrm{g} / \mathrm{ml})$ following treatment with RNaseA $(100 \mu \mathrm{g} / \mathrm{ml})$. The analysis of cell cycle distribution of $3 \times 10^{4}$ cells was carried out using a flow cytometer (Cytomics FC 500; Beckman Coulter, Inc.). Cell apoptosis was evaluated using an Annexin V-FITC/PI kit (cat. no. C1062M, Beyotime Institute of Biotechnology). In brief, $\sim 1 \times 10^{5}$ cells were harvested and resuspended in $195 \mu \mathrm{l}$ of assay buffer. Subsequently, $5 \mu 1$ of Annexin V-FITC and $10 \mu \mathrm{l}$ of PI were added and mixed gently before incubated at room temperature in dark for $25 \mathrm{~min}$. Samples were analyzed immediately by a flow cytometer (Cytomics FC 500; Beckman Coulter, Inc.). Metaphase chromosome spreads were prepared, fixed and stained with Giemsa.

Histone phosphorylation and epigenetic immunofluorescence analysis. The fibroblasts were fixed with $4 \%$ paraformaldehyde, followed by permeabilization with $0.1 \%$ Triton $\mathrm{X}-100(\mathrm{v} / \mathrm{v})$ for $10 \mathrm{~min}$ and blocking with $3 \% \mathrm{BSA}(\mathrm{w} / \mathrm{v}$, Sigma-Aldrich; Merck KgaA). Cells were incubated with the following primary antibodies for $2 \mathrm{~h}$ at room temperature or overnight at $4^{\circ} \mathrm{C}$ : Epigenetic markers, anti-histone acH3K9 (1:200; Santa Cruz Biotechnology, Inc.) and anti-histone meH3K9 (1:500; Abcam), and the histone phosphorylation markers, anti-phosphorylated (p)-H3S10 (1:200; Santa Cruz Biotechnology, Inc.) and anti-p-H3S28 (1:500; Abcam). The catalog numbers for all primary antibodies are presented in Table SI. Subsequently, the cells were incubated with 488/-labeled secondary antibody (1:500; cat. no. A21206, Invitrogen; Thermo Fisher Scientific, Inc.) for $1 \mathrm{~h}$ at $37^{\circ} \mathrm{C}$. The cell nucleus was counterstained with $10 \mu \mathrm{g} / \mathrm{ml}$ PI for $10 \mathrm{~min}$. The results of the immunofluorescence staining were observed under a confocal microscope (TE-2000-E, Nikon, Inc.). In addition, the effects of RepSox on the TGF- $\beta$ pathway and histone modifications were also detected via incubating with anti-Smad1 (1:200; Acris Antibodies; OriGene Technologies, Inc.), anti-p-Smad3 (1:500; BIOSS), anti-acH3K9 (1:200; Santa Cruz Biotechnology, Inc.) and anti-meH3K9 (1:500; Abcam) antibodies according to the manufacturer's protocols for direct staining of using flow cytometry (Cytomics FC 500; Beckman Coulter, Inc.), respectively.

RepSox treatment and detection of adipocyte differentiation. For adipogenic differentiation, the fibroblasts were pre-treated with $15 \mu \mathrm{M}$ RepSox for three days, and then further cultured for 14 days in adipocyte-inducing differentiation (AID) medium supplemented with $1.7 \mathrm{mM}$ insulin, $1 \mathrm{mM}$ dexamethasone and $0.5 \mathrm{mM} 3$-isobutyl-1-methylxanthinethe. The formation of lipid droplets was assessed using Oil Red O staining kit (cat. no. C0158S, Beyotime Institute of Biotechnology) according to the manufacturer's instructions, and the expression levels of the fat-specific genes, lipoprotein lipase (LPL) and peroxisome proliferator-activated receptor $\gamma$ (PPAR $\gamma$ ), were detected by reverse transcription-quantitative PCR (RT-qPCR).

Influence of RepSox on the BMP and TGF- $\beta$ pathways during adipocyte differentiation. The effects of RepSox on the BMP and TGF- $\beta$ pathways during adipocyte differentiation were evaluated by western blot analysis and RT-qPCR. Total proteins 
from the different groups were extracted using the total protein extraction kit according to the manufacturer's instructions (cat. no. P0028; Beyotime Institute of Biotechnology) and the concentration of each sample was determined using the BCA kit (P0010, Beyotime Institute of Biotechnology). $\beta$-actin (1:5,000; Affinity Biosciences, Inc.) was used as internal reference protein. Equal amounts of protein $(40 \mu \mathrm{g})$ were separated with $10 \%$ SDS-polyacrylamide gel electrophoresis and transferred to PVDF membranes. The membranes were blocked with $5 \%$ skimmed milk powder diluted in TBST at room temperature for $1 \mathrm{~h}$, and incubated with the following primary antibodies overnight at $4^{\circ} \mathrm{C}$ : Anti-Smad1, anti-Smad2 (1:300; Acris Antibodies; OriGene Technologies, Inc.), anti-p-Smad3, anti-Smad7, anti-BMP2 and anti-BMP3 (1:500; BIOSS), pluripotent markers anti-octamer-binding transcription factor 4 (Oct4), anti-Sox2, anti-L-Myc (1:1,000; Abcam) and anti-Nanog (1:500; Cell Signaling Technology, Inc.), as well as cell surface markers anti-E-cadherin, anti-N-cadherin, anti-CTGF and anti-collagen I (1:500; BIOSS). The blots were developed using Beyo ECL Plus reagent (cat. no. P0018M, Beyotime Institute of Biotechnology, Inc.) and analyzed using Bio-Rad Quantity One software (Bio-Rad Laboratories, Inc.). The catalog numbers for all primary antibodies are presented in Table SI (22).

A subset of candidate genes specific to the BMP and TGF- $\beta$ pathways were used to initially evaluate the effects of RepSox on the plasticity of sheep fibroblasts by semi-quantitative PCR. Total RNA was extracted from the different groups treated with RepSox using TRIzol ${ }^{\circledR}$ reagent (cat. no. 15596026, Invitrogen; Thermo Fisher Scientific, Inc.), and reverse transcribed into cDNA using a PrimeScript RT reagent kit (cat. no. RR037A, Takara Bio, Inc.) as described in the protocol. An Applied Biosystems QuantStudio 6 Flex thermocycler was employed to perform quantitative PCR using a TB Green Premix Ex Taq kit (cat. no. RR42LR, Takara Bio, Inc.). The PCR conditions were as follows: Denaturation at $94^{\circ} \mathrm{C}$ for $30 \mathrm{sec}$, annealing at $55-63.5^{\circ} \mathrm{C}$ for $30 \mathrm{sec}$ and elongation at $72^{\circ} \mathrm{C}$ for $1 \mathrm{~min}$ for a total of 33 cycles with an initial denaturation at $95^{\circ} \mathrm{C}$ for $4 \mathrm{~min}$ and a final extension of $5 \mathrm{~min}$. Amplified fragments were then subjected to electrophoresis on a $1 \%$ agarose gel stained with Gel-Red (cat. no. D0140, Beyotime Institute of Biotechnology, Inc.) for visualization (23), and the primers used for PCR are presented in Table SII.

Bioinformatics analysis on RNA-sequencing. Total RNA was extracted from two samples, DMSO control (DC) and $15 \mu \mathrm{M}$ RepSox for 3 days (Rep3), using the Arcturus PicoPure RNA Isolation kit (Applied Biosystems; Thermo Fisher Scientific, Inc.). Two cDNA libraries were constructed at Sangon Biotech Co., Ltd., subjected to 125 bp end sequencing using an IlluminaHiSeq ${ }^{\mathrm{TM}} 2500$ platform (Illumina, Inc.). Raw reads were filtered to obtain high-quality clean reads. Each sample was then mapped to a reference genome with TopHat2 (version 2.0.3.12) (24). The expression levels were normalized using the Fragments Per Kilobase of transcript per Million mapped reads method. DESeq (an R package, http://www.rproject.org/) was used to evaluate differentially expressed genes (DEGs) in both groups, of which genes with a fold-change $\geq 2$ and a false discovery rate $<0.05$ were deemed to be the significant
DEGs (25). The Gene Ontology (GO) classifications were compared between the upregulated and downregulated unigenes using the Web Gene Ontology Annotation Plot method. clusterProfiler (version 3.8.1) from the R software package was used to annotate the pathways related to the DEGs and compared against the Kyoto Encyclopedia of Genes and Genomes (KEGG) database (26). To understand the dynamic changes and absolute expression magnitude between the two samples, the genes associated with the top 25 pathways were separated for further research.

Statistical analysis. All data are expressed as the mean \pm SD from at least three independent experiments. Statistical significance $(\mathrm{P}<0.05)$ was determined using a paired Student's t-test or one-way ANOVA with Dunnett's for multiple pairwise comparisons. GraphPad Prism 7.0 software (GraphPad Software Inc.) was used for statistical analysis and for the generation of graphs.

\section{Results}

Effects of RepSox on the morphology of sheep fibroblasts. Following RepSox treatment for three days, the sheep fibroblasts acquired a notably different morphology, and transformed from a spindle shape into an elongated shape with more present bunching (Fig. 1A). Moreover, the fibroblasts treated with 10 and $15 \mu \mathrm{M}$ RepSox were more slender in shape, and the microfilament skeleton gradually changed to a parallel arrangement, and displayed a notably different actin organization, as detected by phalloidin labeling staining (Fig. 1B). However, following treatment with $>20 \mu \mathrm{M}$ RepSox for three days, the intercellular space was increased, the cells were more adhesive to the culture plate and formed a poly heap, and cell morphology gradually became flat and their three-dimensional structure was lost (Fig. 1A).

Effects of RepSox on cell proliferation and apoptosis. Cell proliferation was not markedly affected by RepSox, as determined by BrdU indirect immunofluorescence assay (Fig. 1D). Moreover, there were no substantial differences in the rates of cell apoptosis and cell death between the RepSox-treated groups and the DC (Fig. 1E). However, RepSox treatment resulted in a significant increase in the number of cells in the $\mathrm{G}_{2} / \mathrm{M}$ phase $(\mathrm{P}<0.05)$, while the number of cells in the $\mathrm{S}$ phase was slightly lower than that in the DC (Fig. 1F). Chromosome G-Banding analysis demonstrated that the percentage of RepSox-treated diploid cells $(2 n=60)$ was $93.6 \%$ (Fig. 1C). Furthermore, no chromosome aberration was observed, which suggested that fibroblasts treated with RepSox still possessed genetic stability.

RepSox regulates histone epigenetic modifications. Previous studeis have demonstrated that the phosphorylation of H3S10 plays an important role in the initiation of transcription and aggregation of mitotic chromosomes, which is critical for the initiation of the $G_{2}$ phase, by regulating gene transcription activity $(27,28)$. In the present study, compared with the control group, RepSox led to a considerable increase in the level of H3S10 phosphorylation (increased by $95.6 \pm 3.66 \%$; Fig. 2A and B), while H3S28 phosphorylation was reduced by 
A

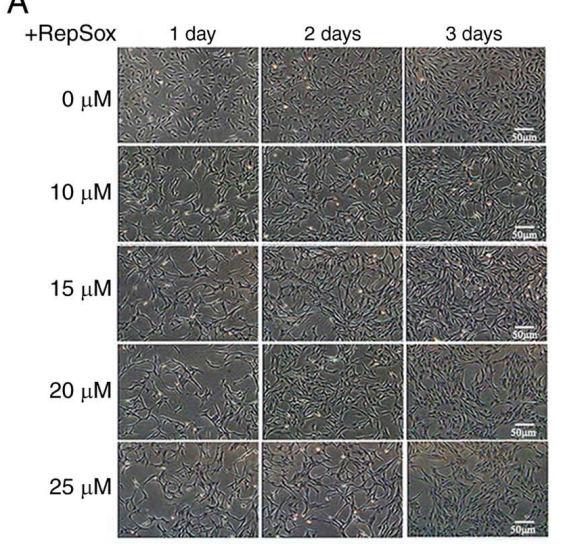

C

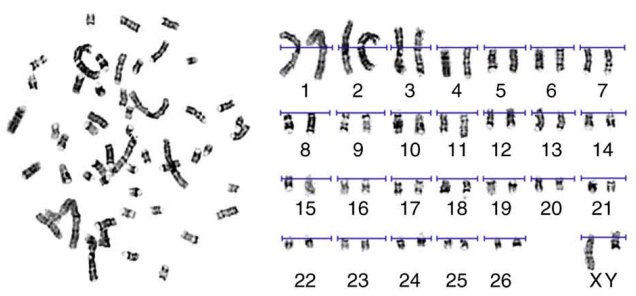

B
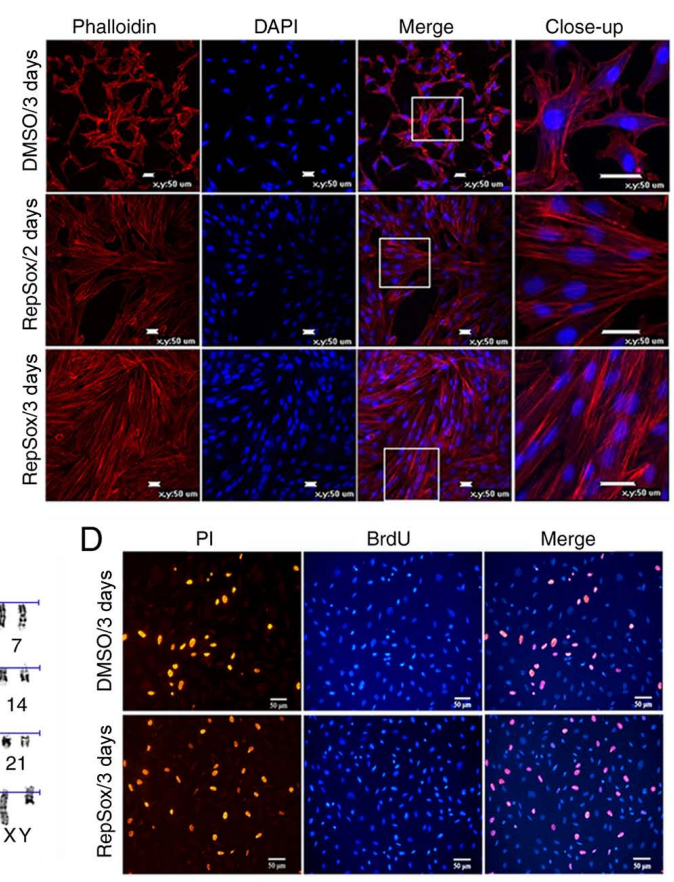

E
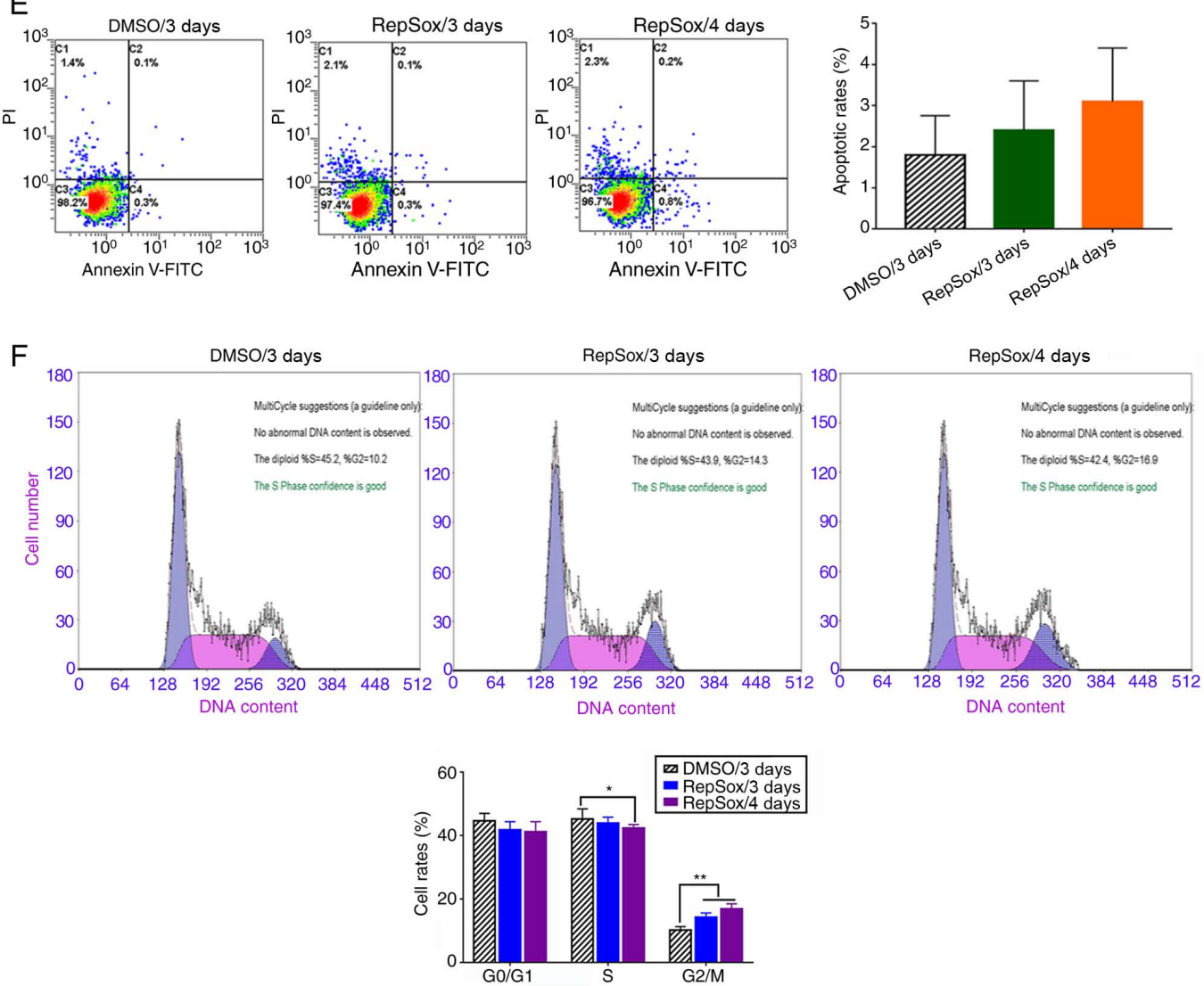

Figure 1. RepSox treatment alters the biological characteristics of sheep fibroblasts. (A) Morphology of fibroblasts transformed from a spindle shape into an elongated state. (B) There was a significant alteration in the organization and orientation of actin filaments after $15 \mu \mathrm{M}$ RepSox treatment for three days. (C) Chromosome G-banding analysis of RepSox-treated cells. (D) Cell proliferation was detected using BrdU indirect immunofluorescence. (E) Apoptosis was detected in the $15 \mu \mathrm{M}$ RepSox treatment group and the DC group using Annexin V-FITC/PI and flow cytometry. (F) Treatment with RepSox resulted in a significant increase in the number of cells in the $\mathrm{G}_{2} / \mathrm{M}$ phase $(\mathrm{P}<0.05)$, while the number of cells in the $\mathrm{S}$ phase was slightly higher than in the DC. DC, DMSO control. ${ }^{*} \mathrm{P}<0.05$ and ${ }^{* *} \mathrm{P}<0.01$, vs. control.

26.3\% (Fig. 2C and D). These results confirmed that RepSox treatment resulted in a marked increase in the number of cells in the $\mathrm{G}_{2} / \mathrm{M}$ phase by regulating histone phosphorylation.
By contrast, the meH3K9 level notably increased by $74.7 \pm 2.38 \%$ (Fig. 2E and F), and the level of acH3K9 acetylation decreased by $64.8 \pm 6.38 \%$ (Fig. $2 \mathrm{G}$ and $\mathrm{H}$ ). There was a 

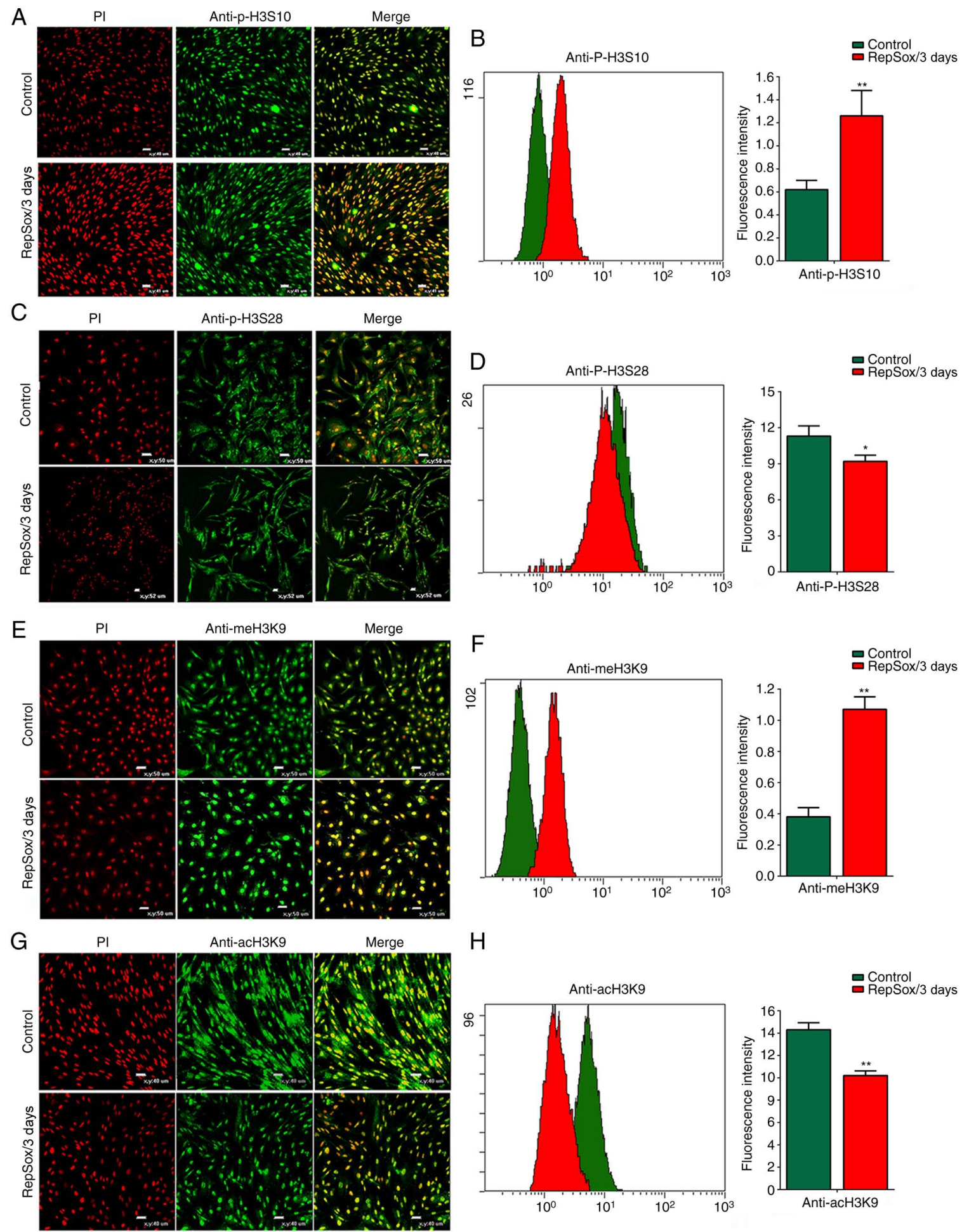

$\mathrm{H}$
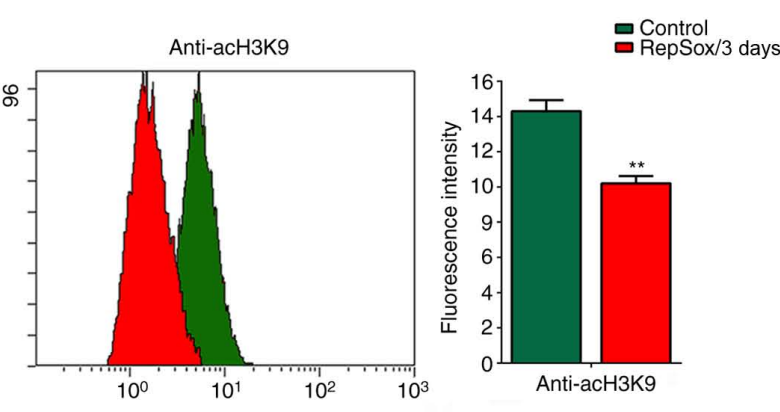

Figure 2. Histone phosphorylation and epigenetic alterations in RepSox-treated fibroblasts. (A and C) Level of histone H3S10 and H3S28 phosphorylation in RepSox-treated cells and control cells. PI, red; anti-P-H3S10 and anti-P-H3S28 immunofluorescence, green. (B and D) Histone H3S10 phosphorylation increased by $95.6 \pm 3.66 \%$ and H3S28 phosphorylation decreased by $26.3 \pm 4.84 \%$ compared with the control group, as determined via flow cytometry analysis. (E and F) Intensity of acH3K9 and meH3K9 signals in RepSox-treated cells and control group. Fibroblasts were treated with RepSox for 3 days. PI, red; anti-acH3K9 and anti-meH3K9 immunofluorescence, green. ( $\mathrm{G}$ and H) Cells were stained with acH3K9 and meH3K9, and analyzed by flow cytometry. ${ }^{*} \mathrm{P}<0.05$ and ${ }^{* *} \mathrm{P}<0.01$, vs. control.

substantially negative association between H3K9 acetylation and methylation.

RepSox pre-treatment enhances the differentiation potential towards adipocytes. RepSox-treated fibroblasts could differentiate into mesodermal lineage adipocytes under specific AID conditions. The induced cells exhibited multipolar projections, the volume became large and the intracellular lipid droplets in the cytoplasm gradually increased after induced differentiation for 10 days. Over time, small 
A
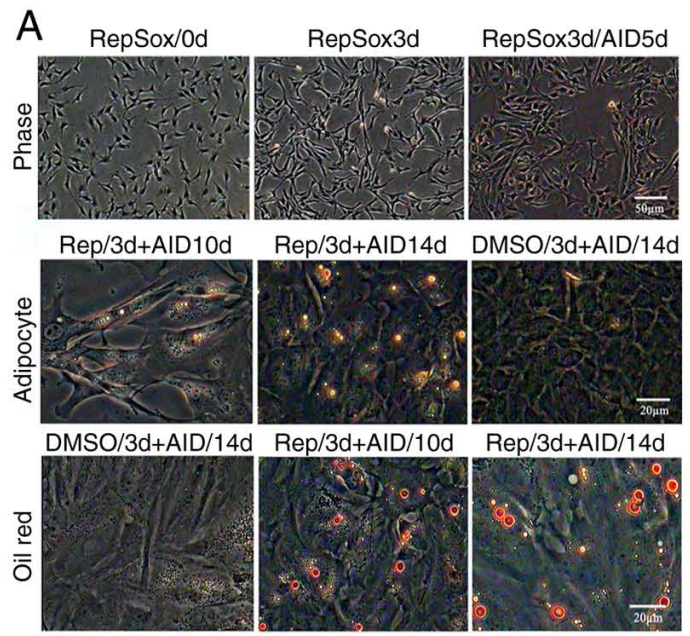

Rep/3d+AID14d DMSO/3d+AID/14d
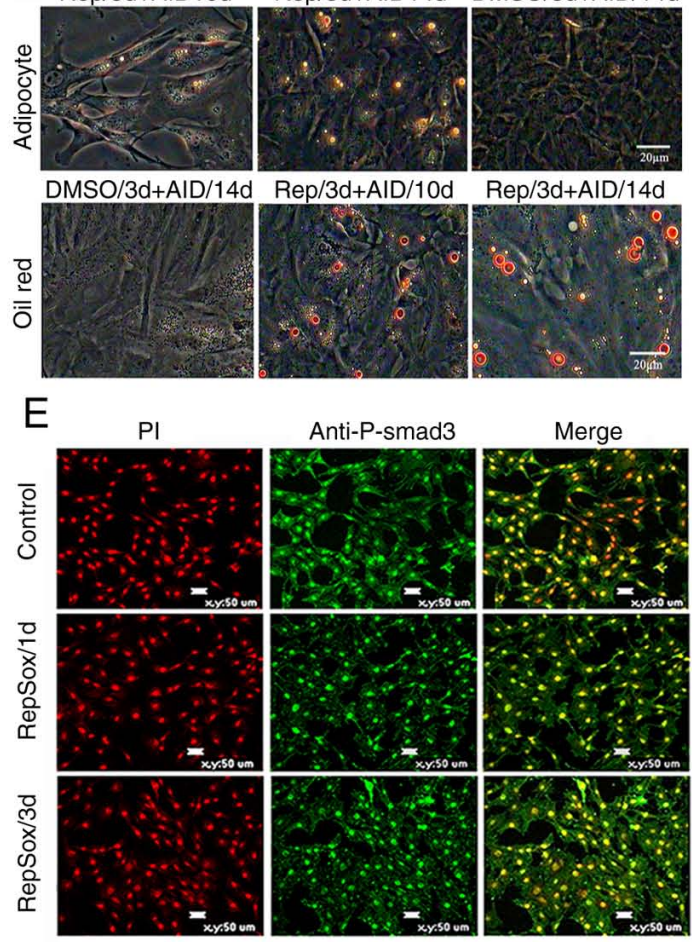

B
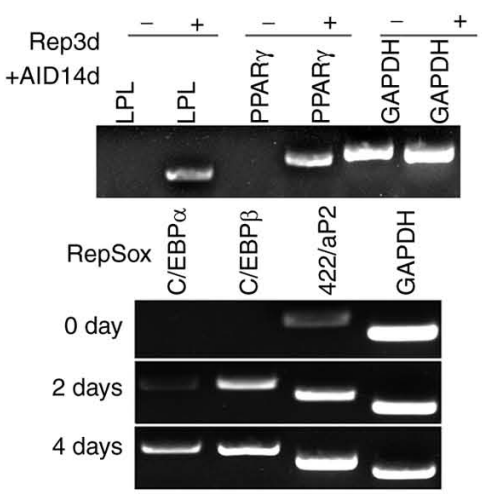

C
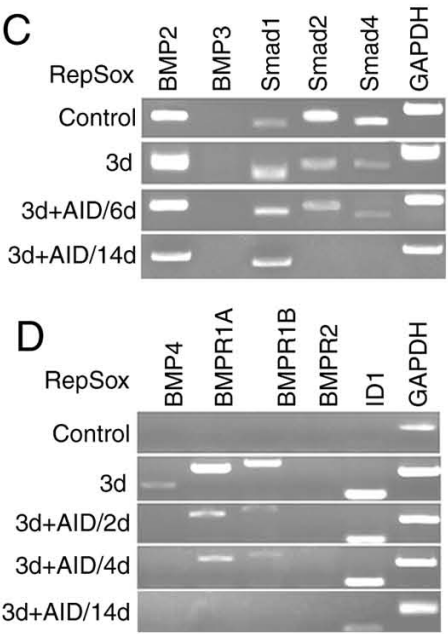

$\mathrm{F}$
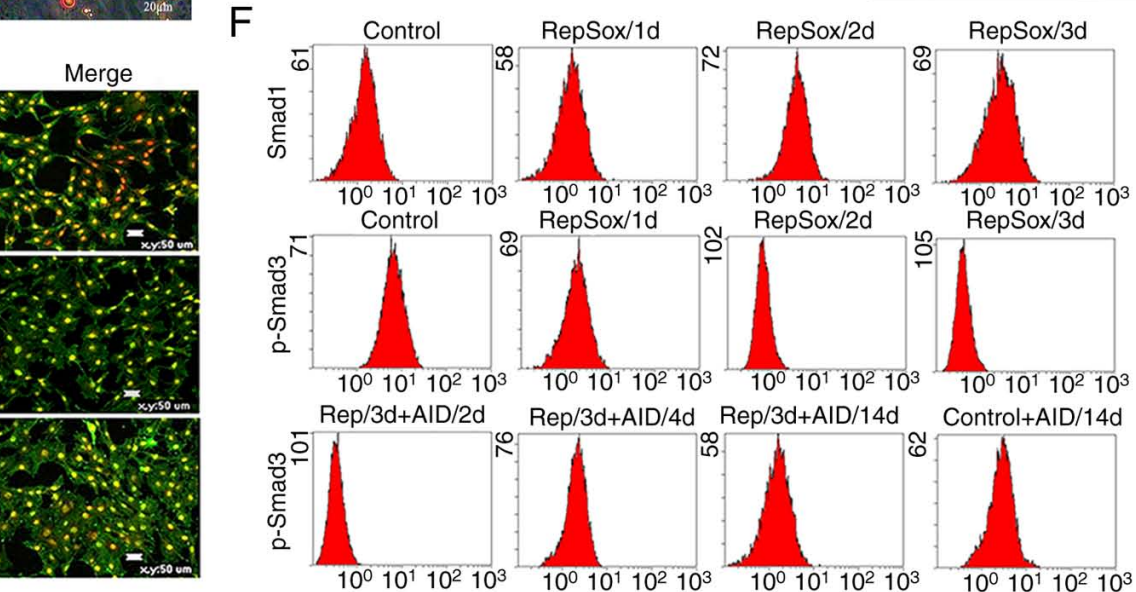

G
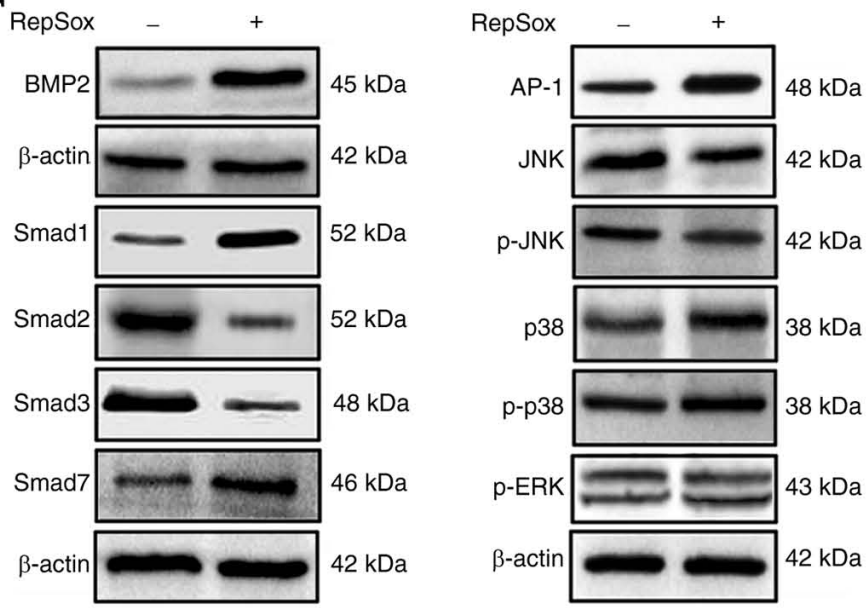

$\mathrm{H}$

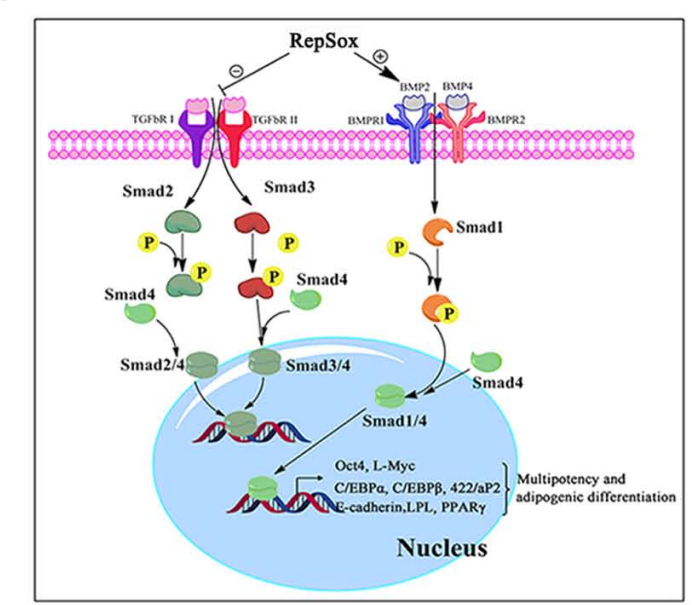

Figure 3. RepSox pretreatment promotes the differentiation potential of SAFs toward adipocytes. (A) Fibroblasts were pretreated with $15 \mu$ M RepSox for three days, and then further cultured for 14 days in adipocyte-inducing differentiation. Lipid droplets were confirmed by Oil Red O staining. (B) Expression levels of multiple adipogenic cell marker genes were analyzed via semi-quantitative PCR. (C) Expression levels of Smad2 and Smad4 were downregulated in response to RepSox treatment. (D) Expression levels of BMP2, BMP4, BMPR1A, BMPR1B and ID1 were markedly upregulated following RepSox treatment and at the early stage of adipogenesis. (E) The expression of p-Smad3 markedly decreased following prolonged treatment with RepSox. (F) Cells were co-labeled with Smad and P-Smad3, and analyzed by flow cytometry. (G) Differential expression of key genes of the TGF- $\beta$ and BMP pathways were detected by western blot analysis. (H) RepSox inhibited TGF- $\beta$ signaling and activated BMP signaling in SAFs. SAF, sheep adult fibroblasts; BMP, bone morphogenetic protein; ID1, DNA-binding protein inhibitor ID-1; TGF- $\beta$, transforming growth factor- $\beta$; P-, phosphorylated; AID, adipocyte-inducing differentiation medium; $d$, day.

lipid droplets gradually gathered into bunches and formed large lipid droplets, and the nuclei were crowded to the edge of the cell. Moreover, lipid droplets in induced adipocytes were confirmed by Oil Red O staining (Fig. 3A). The cells expressed multiple adipogenic markers, including LPL and
PPAR $\gamma$ (Fig. 3B). Previous research has reported that C/EBP $\beta$ is transiently induced during the early phase of adipocyte differentiation, while $\mathrm{C} / \mathrm{EBP} \alpha$ is upregulated during the terminal stages of adipogenesis (29). The present study found that RepSox treatment for two and four days led to a marked 

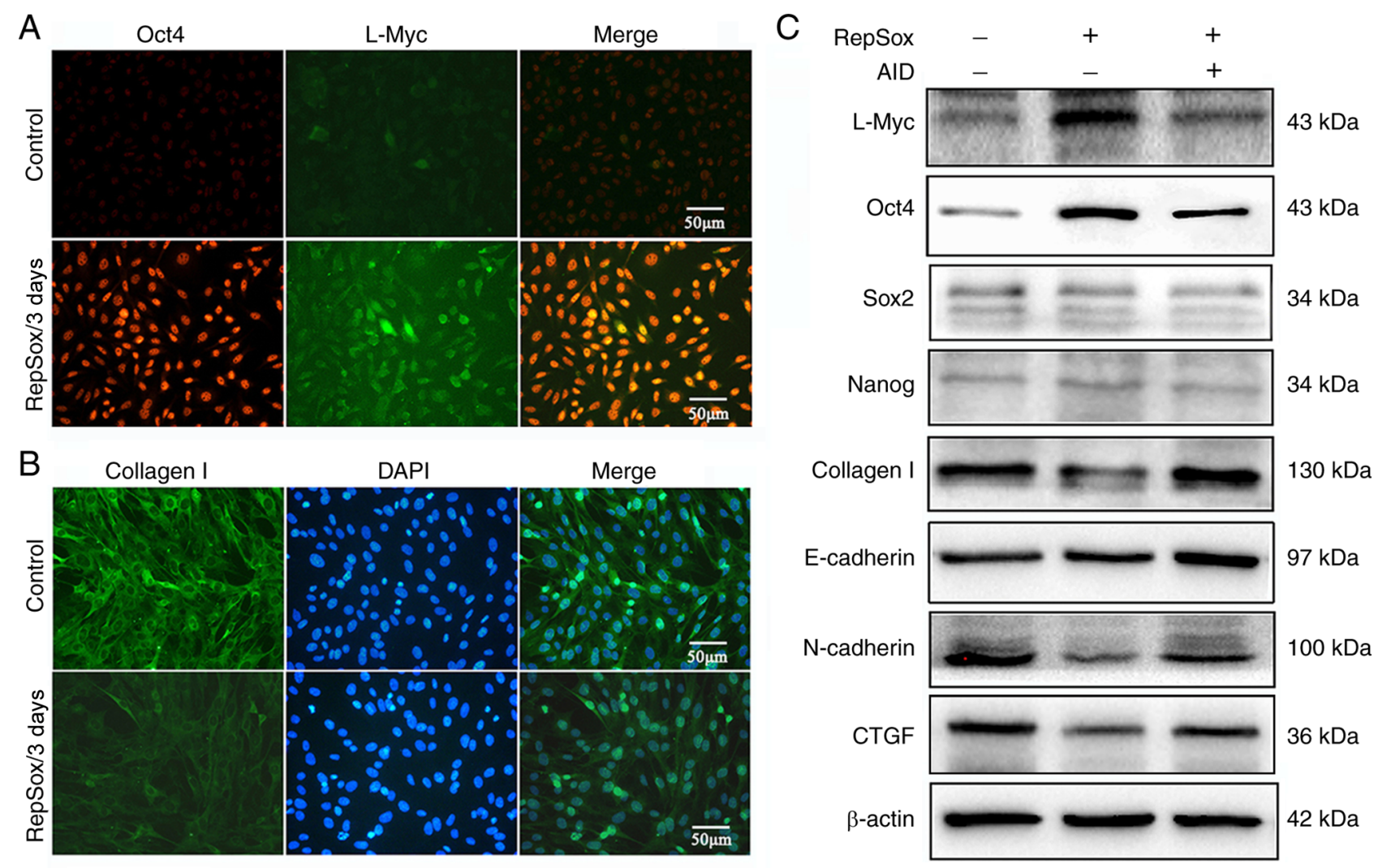

$\mathrm{D}$

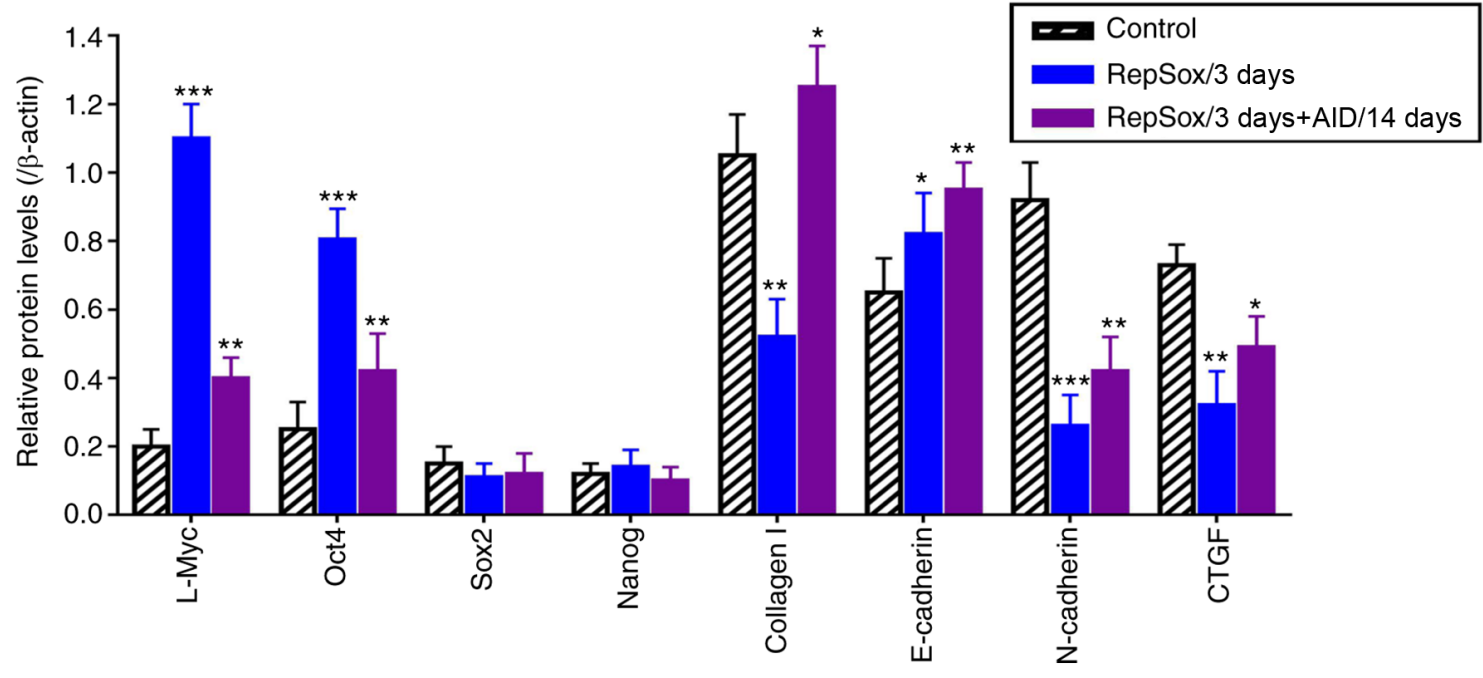

Figure 4. RepSox treatment upregulates Oct4 expression and accelerates adipogenesis by inducing MET. (A) Expression levels of pluripotent markers Oct4 and L-Myc were analyzed via immunocytochemistry. (B) Expression of Collagen I was markedly decreased following RepSox treatment. (C) Expression levels of pluripotent markers and MET-related proteins were analyzed by western blot analysis. (D) Scanning densitometry was used for the semi-quantitative analysis of western blot analysis data. ${ }^{*} \mathrm{P}<0.05,{ }^{* * *} \mathrm{P}<0.01$ and ${ }^{* * * *} \mathrm{P}<0.001$, vs. control. MET, mesenchymal-epithelial transition; AID, adipocyte-inducing differentiation medium.

upregulation in the levels of $\mathrm{C} / \mathrm{EBP} \alpha$ and $\mathrm{C} / \mathrm{EBP} \beta$ (Fig. 3B). Moreover, the expression of adipogenic transcription factor 422/aP2 was also substantially increased, which is regulated by C/EBP $\alpha$ (Fig. 3B).

RepSox treatment inhibits TGF- $\beta$ and promotes BMP signaling in SAFs. Following treatment with $15 \mu \mathrm{M}$ RepSox for three days, the expression levels of components of the TGF- $\beta$ signaling pathway were markedly decreased, including Smad2 (0.06-0.29-fold of control) and Smad3 (0.08-0.25-fold) (Fig. 3C and G). Furthermore, the expression of p-Smad3 was notably downregulated following prolonged treatment with
RepSox and AID induction (Fig. 3E and F). Additionally, an evident increase in the levels of Smad1 protein was also observed (Fig. 3G). However, a notable increase in the expression of BMP2 was also observed, as opposed to BMP3, in response to RepSox treatment (Fig. 3C). The expression levels of $B M P 4$, $B M P R 1 A, B M P R 1 B$ and DNA-binding protein inhibitor ID-1 (ID1) were evidently upregulated following RepSox treatment and at the early stage of adipogenesis (Fig. 3D). Moreover, the expression levels of BMP pathway-related factors were notably downregulated, and no expression was observed at the late stage of adipogenesis (Fig. 3C and D), indicating that the BMP pathway was not active in the later stages of adipogenesis. 
A

$\mathrm{BP}$

CC

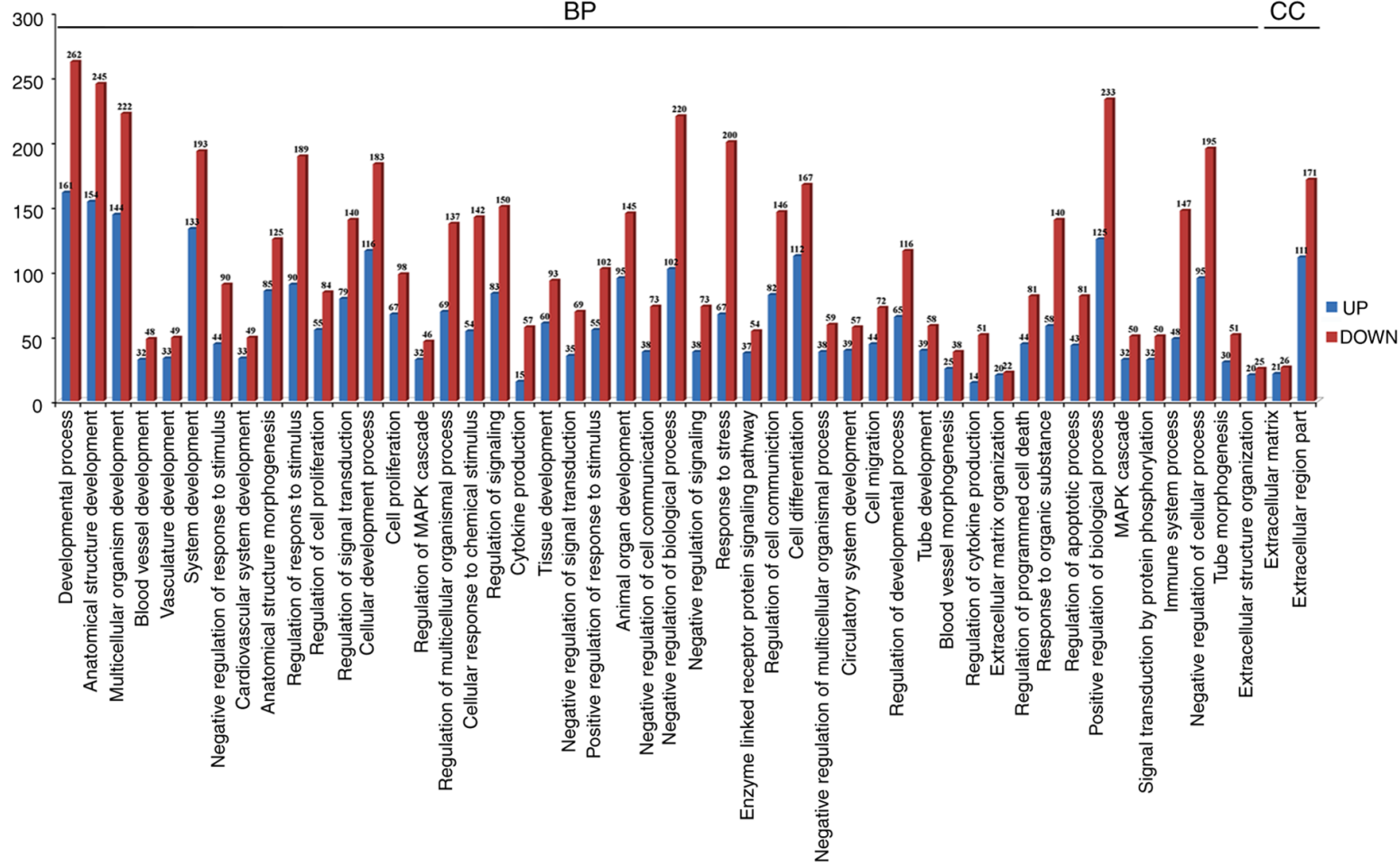

B

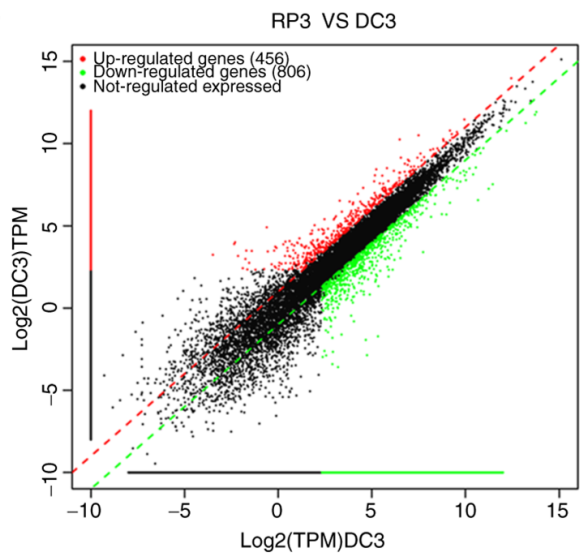

C

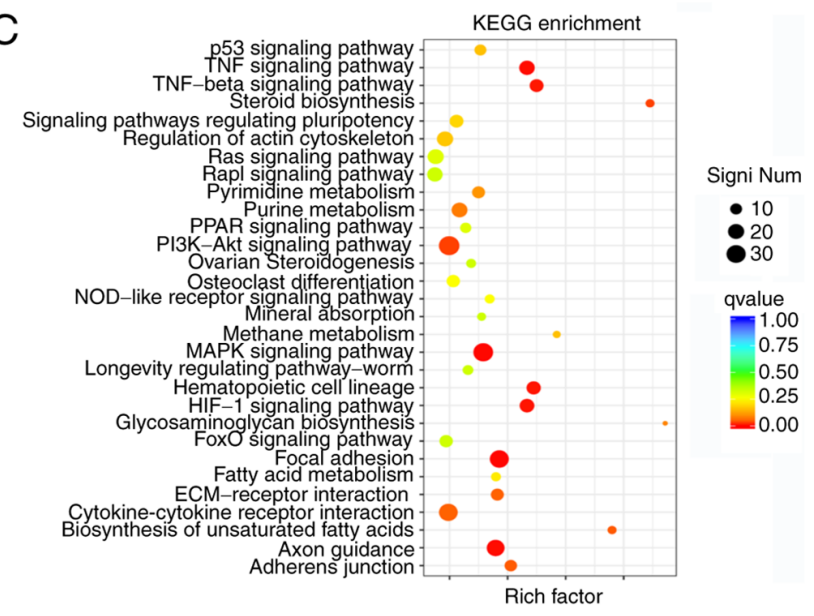

D

Log10(pvalue)

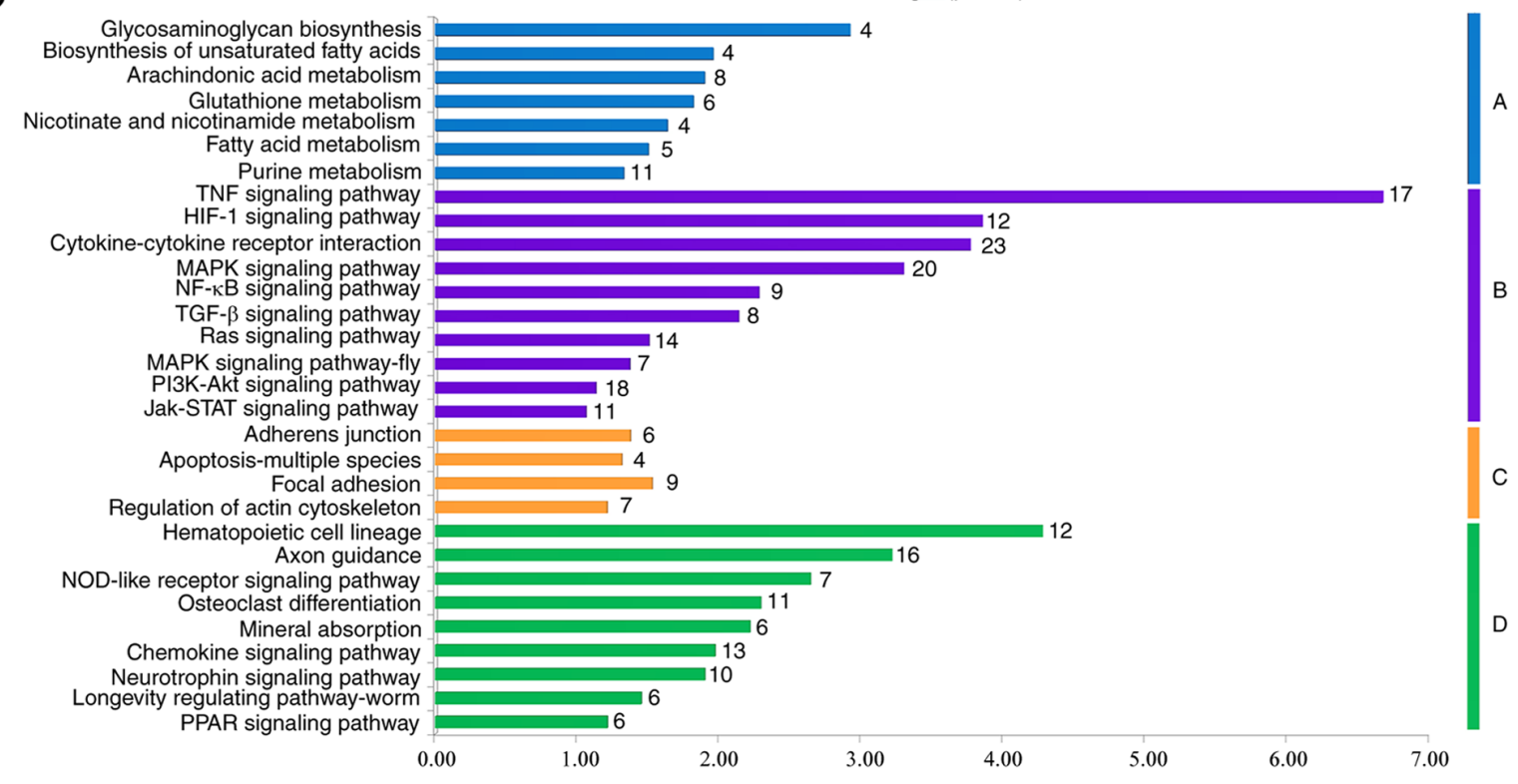

Figure 5. Continued. 


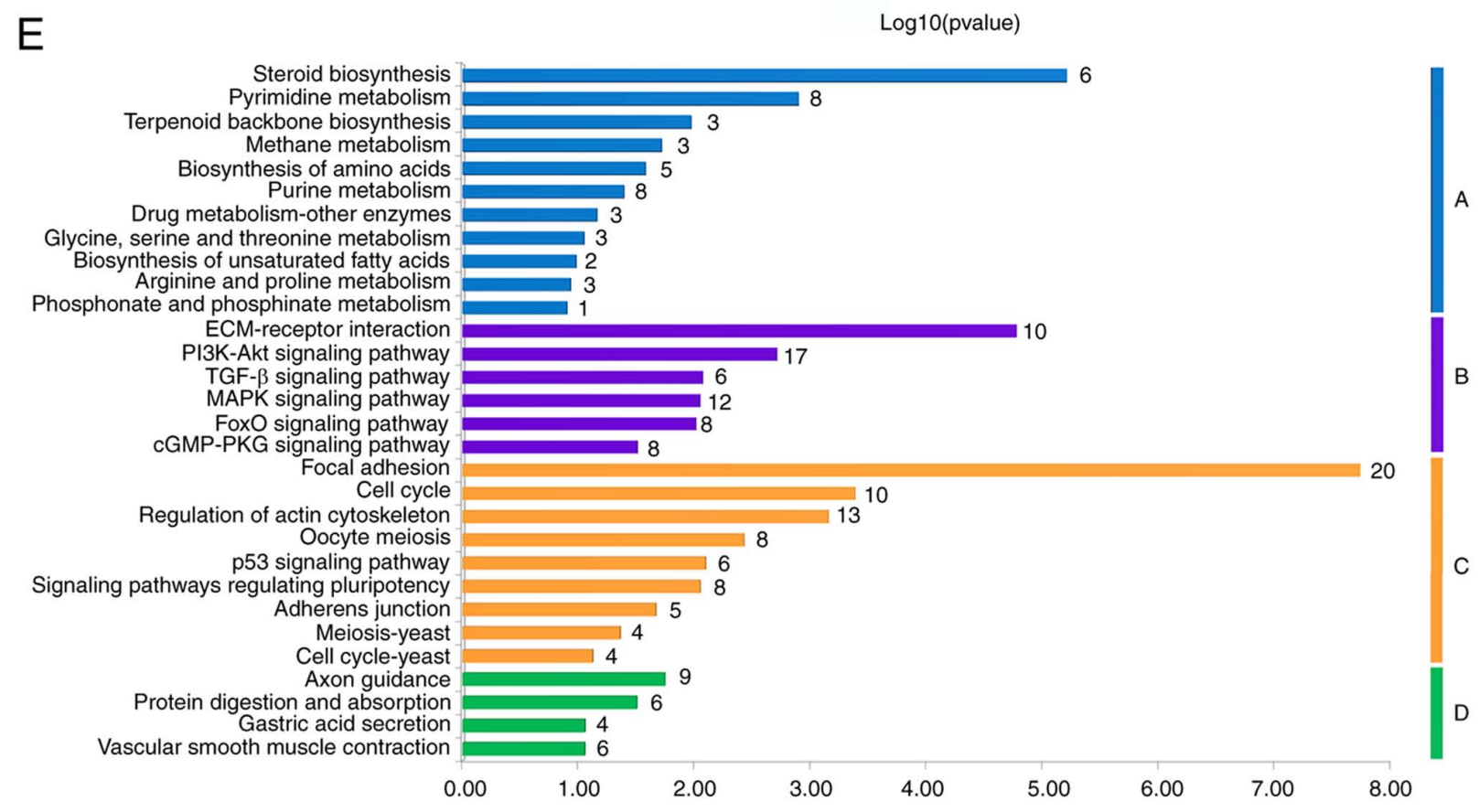

Figure 5. Pathway enrichment analysis of DEGs between Rep3 and DC groups using RNA-sequencing. (A) GO enrichment revealed that DEGS were associated with $50 \mathrm{GO}$ terms. (B) Digital expression levels of unigenes. (C) KEGG analysis identified the enriched pathways of DEGs among the four groups. (D) A total of 30 enriched pathways consisting of upregulated genes were classified into five categories that are essential for cell characteristics. (E) A total of 30 enriched pathways consisting of downregulated genes were further classified into five categories. DEG, differentially expressed gene; Rep3, RepSox treatment for 3 days; DC, DMSO control; GO, Gene Ontology; KEGG, Kyoto Encyclopedia of Genes and Genomes.

MAPK signaling pathways, including the ERK, JNK and p38 sub-pathways, are some of the key pathways involved in adipogenesis (30). In the present study, RepSox reduced the phosphorylation of Smad3 (Fig. 3E) and JNK, but not ERK or p38 activation (Fig. 3G). Furthermore, the expression of Smad7, one of the I-Smad proteins, which is able to block TGF- $\beta$ signaling pathway selectively and replace Sox 2 to enhance reprogramming, was reinforced in RepSox-treated fibroblasts (Fig. 3G). These results suggested that RepSox regulated adipogenesis by inhibiting the Smad3 and JNK/AP-1 pathways.

RepSox treatment promotes Oct4 expression and accelerates adipogenesis by inducing MET. RepSox markedly promoted the expression of Oct4 (4.5-fold, Fig. 4D); however, Sox 2 and Nanog expression were not detected (Fig. 4A and B), which indicated that the activation of Oct 4 may play a crucial role in the acquisition of cell multipotency. These results also suggested that RepSox did not replace Sox 2 by directly activating endogenous Sox 2 . By contrast, it was found that RepSox did increase the expression of L-Myc by 5 -fold, which is a close homolog of cMyc that can functionally replace it in reprogramming. Therefore, although RepSox probably functions at the level of the initial somatic cell population to replace Oct 4 and cMyc, it does not act by replacing Sox 2 and Nanog.

Previous studies have demonstrated that the process of EMT is dependent on autocrine TGF- $\beta$ signaling $(31,32)$. Thus, in the present study, it was hypothesized that RepSox regulates the expression of E-cadherin and $\mathrm{N}$-cadherin by regulating the BMP family. In addition, the expression levels of connective tissue growth factor (CTGF) and collagen I were markedly decreased following treatment with RepSox (Fig. 4B-D). Moreover, Smad7 constitutively formed a complex with the TGF- $\beta$ receptors, and the inhibitory effect of Smad7 on the promoter activity of collagen I was enhanced in RepSox-treated fibroblasts. Thus, it was demonstrated that RepSox exerted the most potent inhibitory effects on TGF- $\beta$-induced expression of target genes (CTGF and collagen I) to regulate cell morphology and cell junctions.

High-throughput RNA sequencing for DEGs between RepSox treatment and control groups. GO and KEGG analysis revealed that the six most enriched pathways between the Rep3 and DC groups were associated with 'Focal adhesion', 'MAPK signaling pathway', 'TGF- $\beta$ signaling pathway', 'PI3K/Akt signaling pathway', 'Regulation of actin cytoskeleton' and 'Ras signaling pathway'. Moreover, upregulated DEGs were mainly enriched in the PI3K/Akt signaling pathway, while the MAPK signaling pathway was the most enriched pathway for the downregulated DEGs. Both the PI3K/Akt and MAPK signaling pathways participated in the regulation of a number of cellular processes, such as cell proliferation regulation, cell junction, cell morphogenesis, cell migration and differentiation. The pathways labeled with red boxes indicate the most enriched DEGs between the two groups (Fig. 5C).

A total of 50 enriched GO terms and scatter plots of DEGs between the Rep3 and DC groups are shown in Fig. 5A and B. Furthermore, the top 25 upregulated and top 25 downregulated genes are presented in Fig. 6B. Additionally, 30 enriched pathways consisting of upregulated genes were further classified into four categories that are essential for cell functions: 

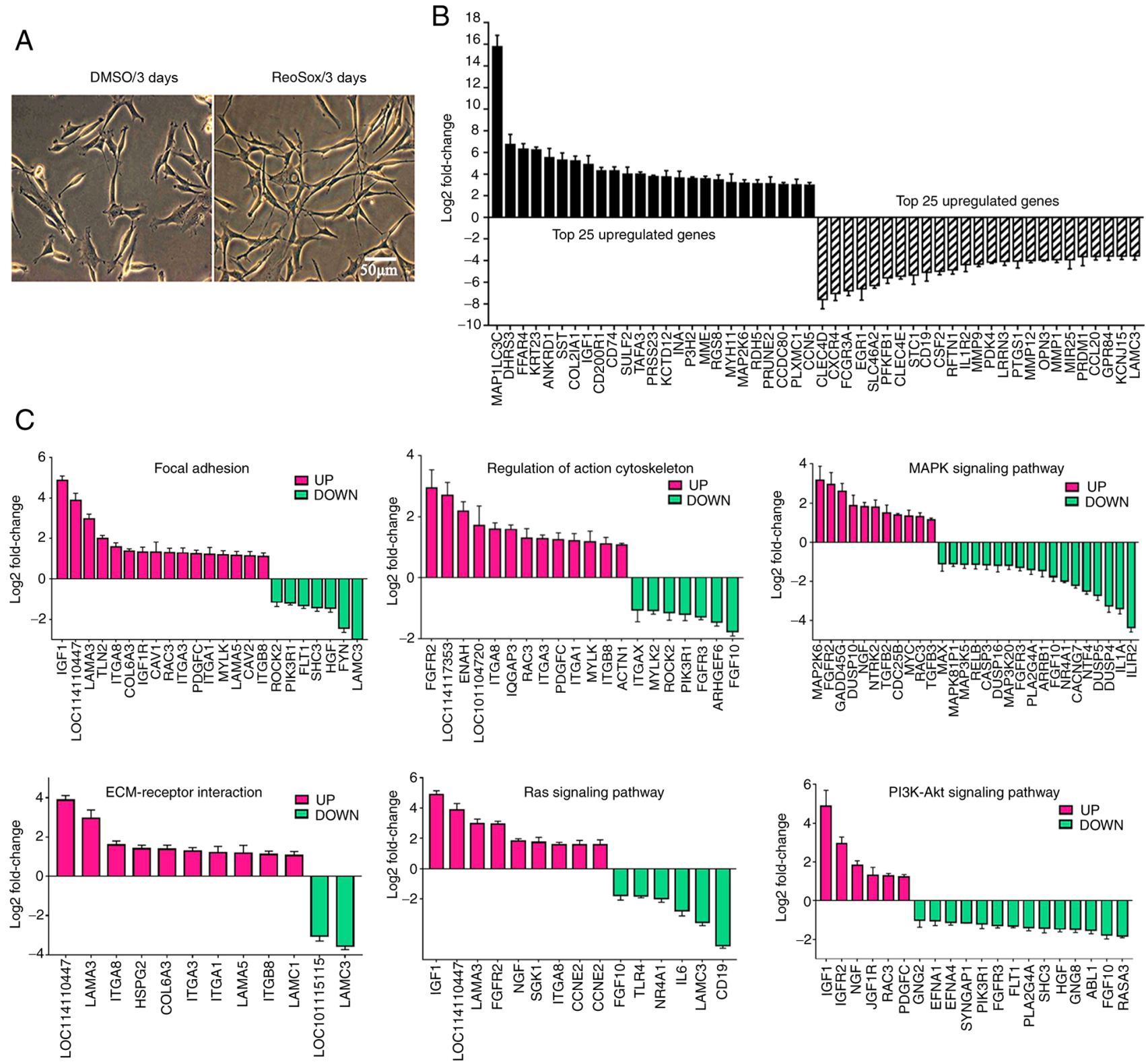

Figure 6. Characteristic comparisons of the RNA-sequencing dataset among the four groups. (A) Comparison of cell morphology between RepSox-treated fibroblasts and control cells for 3 days. (B) The top 25 upregulated and downregulated genes between Rep3 and DC groups. (C) DEGs involved in 'Focal adhesion', 'Regulation of actin cytoskeleton', 'MAPK signaling pathway', 'ECM-receptor interaction', 'Ras signaling pathway' and 'PI3K-Akt signaling pathway' were identified. DEG, differentially expressed gene; Rep3, RepSox treatment for 3 days; DC, DMSO control.

'Metabolism', 'Environmental Information Processing', 'Cellular Processes' and 'Organismal Systems' (Fig. 5D). Similarly, 30 enriched pathways consisting of downregulated genes were also further classified into the same four categories (Fig. 5E).

The majority of genes involved in the 'Regulation of actin cytoskeleton', 'MAPK signaling pathway', 'Focal adhesion' and 'ECM-receptor interaction' were significantly up-or downregulated in the RepSox-treated fibroblasts (Fig. 6C), which suggested that RepSox markedly promoted the cell morphogenesis of sheep fibroblasts (Fig. 6A). Moreover, these DEGs involved in various metabolic processes, such as 'Pyrimidine metabolism', 'Steroid biosynthesis', 'Methane metabolism' and 'Purine metabolism', were markedly upregulated in RepSox-treated fibroblasts, which indicates that high concentrations of RepSox could cause changes in cell metabolism (Fig. 5D). In addition, the DEGs involved in most signaling pathways, such as PI3K-Akt, MAPK, Ras and TGF- $\beta$ signaling pathways, were markedly downregulated in the RepSox-treated fibroblasts, which suggests that RepSox can affect cell characteristics by altering multiple signaling pathways (Fig. 5E).

\section{Discussion}

The small molecule, RepSox, can notably improve the efficiency of mouse fibroblast differentiation into iPSCs by inducing the expression of Nanog (8). However, the results of the present study revealed that RepSox markedly increased the expression of Oct4 (4.5-fold) and L-Myc (5.0-fold), although the expression levels of Sox 2 and Nanog were not markedly different. These results indicated the importance of Oct 4 in the 
acquisition of cell multipotency, and RepSox did not directly activate the expression of endogenous Sox 2 and Nanog in the sheep fibroblasts. In addition, RepSox increased the level of histone H3S10 phosphorylation and reduced H3S28 phosphorylation. Moreover, the meH3K9 level notably increased, and the levels of acH3K9 acetylation decreased. Therefore, the RepSox induced-differentiation of fibroblasts into multipotent progenitor-type cells may be partly attributed to the activation of histone methylation, and the reduction of histone acetylation.

RepSox also exerted a marked effect on the morphology conversion of sheep fibroblasts. Cell morphology gradually transformed from a spindle shape into a considerably elongated state, and the cells gradually became flat, losing their three-dimensional structure following treatment with increasing concentrations of RepSox. In addition, the expression levels of CTGF and collagen I were markedly decreased following treatment with RepSox. High-throughput RNA sequencing revealed that the DEGs were mainly involved in 'Regulation of actin cytoskeleton', 'MAPK signaling pathway', 'Focal adhesion' and 'ECM-receptor interaction'. Thus, it could be hypothesized that the plasticity of RepSox-treated fibroblast cells could be tightly related to cell morphology. Moreover, the DEGs were markedly downregulated in the majority of signaling pathways of fibroblasts, such as PI3K/Akt, MAPK, Ras and TGF- $\beta$ signaling pathways, which could indicate that RepSox promoted the plasticity of sheep fibroblasts and markedly upregulated components linked to stem cell maintenance by regulating multiple signaling pathways. However, no substantial differences in cell apoptosis and cell death were observed, which indicated that RepSox treatment did not cause irreversible damage to fibroblasts. TGF- $\beta$ is a multifunctional regulator of the TGF- $\beta$ superfamily that regulates a variety of cellular functions, including cell proliferation, differentiation, apoptosis, matrix synthesis and the immune response (33). Smad proteins have been identified as intracellular mediators for members of the TGF- $\beta$ superfamily. Moreover, the phosphorylation and nuclear export of Smads can be used as an indicator of TGF- $\beta$ pathway activation. Previous reports demonstrated that RepSox inhibited the TGF- $\beta$ pathway by inhibiting the phosphorylation of $\operatorname{Smad} 2 / 3$ in murine embryonic fibroblasts. Similarly, RepSox treatment of SAFs led to an evident decrease in the expression of components (Smad2, Smad3 and Smad4) of the TGF- $\beta$ signaling pathway, particularly the level of Smad3 phosphorylation $(34,35)$.

In addition, BMP signaling is an alternative pathway of the TGF- $\beta$ superfamily signaling and is frequently associated with the phosphorylation of Smad1/5/8 instead of Smad2/3. Furthermore, BMPs are associated with stem cell maintenance and have been demonstrated to promote iPSC production in mice (36). Moreover, the present study found that there was a notable increase in the expression of BMP2, instead of BMP3, in response to RepSox treatment. The expression levels of BMP4, BMPR1A, BMPR1B and ID1 were markedly increased upon treatment with RepSox and at the early stage of adipogenesis, which may have further phosphorylated Smad1/5/8 proteins. The process of differentiation from precursor preadipocytes into mature adipocytes follows a precise series of events (37). PPAR $\gamma$ and $\mathrm{C} / \mathrm{EBP} \alpha$ are the most important factors in the regulation of adipogenesis. Moreover, $\mathrm{C} / \mathrm{EBP} \alpha$ is sufficient to trigger the differentiation of preadipocytes into mature adipocytes via the induction of adipogenic transcription factors 422/aP2 and PPAR $\gamma$. In the present study, there was a marked upregulation in the levels of $\mathrm{C} / \mathrm{EBP} \alpha$ and $\mathrm{C} / \mathrm{EBP} \beta$ following RepSox treatment of SAFs for two and four days. Moreover, it was found that the expression levels of $422 / a P 2$ and $P P A R \gamma$ were also markedly increased, which was regulated by $\mathrm{C} / \mathrm{EBP} \alpha$. These data also demonstrated the pivotal function of 422/aP2 and PPAR $\gamma$ in the regulation of adipogenesis.

Previous research has demonstrated that the reprogramming of cells is a result of the inhibition of EMT and facilitation of MET (38). In the present study, RepSox treatment promoted cell conversion from fibroblasts to adipocytes and disrupted the EMT. MET is an early requisite step during the reprogramming of fibroblasts via the activation of the epithelial program. Additionally, BMP signaling has been implicated in the induction of MET by reversing TGF- $\beta$-induced EMT during the initiation phase of reprogramming (39). In the present study, RepSox substantially increased the expression of BMPs, such as BMP2, BMP4 and BMP6, induced the expression of epithelial-related genes (E-cadherin) and inhibited the expression of mesenchymal-related genes ( $\mathrm{N}$-cadherin). These results indicated that BMPs can enhance Oct4-mediated reprogramming and acceleration of adipogenesis by inducing MET in RepSox-treated fibroblasts.

In conclusion, in the present study, RepSox was demonstrated to be a key mediator in promoting the plasticity of SAFs and facilitating adipocyte differentiation via blocking the TGF- $\beta$ /Smad signaling pathway and activating BMP signaling pathways simultaneously.

\section{Acknowledgements}

Not applicable.

\section{Funding}

The present study was supported by the National Natural Science Foundation of China (grant no. 81771381), the project National Infrastructure of Animal Germplasm Resources (year of 2019), Anhui Provincial Natural Science Foundation (grant no. 1908085MH277), and the Natural Science Foundation of the Higher Education Institutions of Anhui Province (grant nos. KJ2017A215 and KJ2019A0322), and the Undergraduate Innovative Training Program of China (grant nos. 201910367005 and 201910367039).

\section{Availability of data and materials}

The datasets used and/or analyzed during the current study are available from the corresponding author on reasonable request. High-throughput RNA sequencing data is available at the Sequence Read Archive (SRA) database under the accession no. PRJNA722043.

\section{Authors' contributions}

CL, WG and XL designed the experiments and revised the manuscript. YG, HZ, YL, TS and YW performed the cell experiments, analyzed the results and drafted the manuscript. $\mathrm{CW}$ and CM performed the statistical analysis. CL and WG 
confirm the authenticity of all the raw data. All authors have read and approved the final manuscript.

\section{Ethics approval and consent to participate}

All experiments were performed according to the protocol approved by the Institutional Animal Care and Use Committee (IACUC) for Ethics of Bengbu Medical College (permit no. 2017-016).

\section{Patient consent for publication}

Not applicable.

\section{Competing interests}

The authors declare that they have no competing interests.

\section{References}

1. Zhou Q, Brown J, Kanarek A, Rajagopal J and Melton DA: In vivo reprogramming of adult pancreatic exocrine cells to beta-cells. Nature 455: 627-632, 2008

2. Wei X, Chen Y, Xu Y, Zhan Y, Zhang R, Wang M, Hua Q, Gu H, Nan F and Xie X: Small molecule compound induces chromatin de-condensation and facilitates induced pluripotent stem cell generation. J Mol Cell Biol 6: 409-420, 2014.

3. Takahashi K and Yamanaka S: Induction of pluripotent stem cells from mouse embryonic and adult fibroblast cultures by defined factors. Cell 126: 663-676, 2006.

4. Ichida JK, Blanchard J, Lam K, Son EY, Chung JE, Egli D, Loh KM, Carter AC, Di Giorgio FP, Koszka K, et al: A small-molecule inhibitor of tgf-Beta signaling replaces sox 2 in reprogramming by inducing nanog. Cell Stem Cell 5: 491-503, 2009.

5. Hou P, Li Y, Zhang X, Liu C, Guan J, Li H, Zhao T, Ye J, Yang W, Liu K, et al: Pluripotent stem cells induced from mouse somatic cells by small-molecule compounds. Science 341: 651-654, 2013.

6. Huangfu D, Maehr R, Guo W, Eijkelenboom A, Snitow M, Chen AE and Melton DA: Induction of pluripotent stem cells by defined factors is greatly improved by small-molecule compounds. Nat Biotechnol 26: 795-797, 2008.

7. Gao Y, Zhang R, Dai S, Zhang X, Li X and Bai C: Role of TGF- $\beta /$ Smad pathway in the transcription of pancreas-specific genes during beta cell differentiation. Front Cell Dev Biol 7: 351, 2019.

8. Maherali $\mathrm{N}$ and Hochedlinger K: Tgfbeta signal inhibition cooperates in the induction of iPSCs and replaces Sox 2 and cMyc. Curr Biol 19: 1718-1723, 2009.

9. Ide M, Jinnin M, Tomizawa Y, Wang Z, Kajihara I, Fukushima S, Hashizume Y, Asano Y and Ihn H: Transforming growth factor $\beta$-inhibitor Repsox downregulates collagen expression of scleroderma dermal fibroblasts and prevents bleomycin-induced mice skin fibrosis. Exp Dermatol 26: 1139-1143, 2017.

10. Zhu HY, Jin L, Guo Q, Luo ZB, Li XC, Zhang YC, Xing XX, Xuan MF, Zhang GL, Luo QR, et al: RepSox improves viability and regulates gene expression in rhesus monkey-pig interspecies cloned embryos. Biotechnol Lett 39: 775-783, 2017.

11. Qin G, Zhao J and Huang J: RepSox increases Porcine cloning efficiency by improving pluripotency of Donor nuclei. Cell Reprogram 21: 181-186, 2019.

12. Luo ZB, Jin L, Guo Q, Wang JX, Xing XX, Xuan MF, Luo QR, Zhang GL, Yin XJ and Kang JD: Cotreatment with RepSox and LBH589 improves the in vitro developmental competence of porcine somatic cell nuclear transfer embryos. Reprod Fertil Dev 30: 1342-1351, 2018.

13. Jajosky AN, Coad JE, Vos JA, Martin KH, Senft JR, Wenger SL and Gibson LF: RepSox slows decay of CD34+ acute myeloid leukemia cells and decreases $\mathrm{T}$ cell immunoglobulin mucin-3 expression. Stem Cells Transl Med 3: 836-848, 2014.

14. Deng M, Liu P, Xiao H, Zhang Y, Wang Y, Zhao J and Xu J: Improving the osteogenic efficacy of BMP2 with mechano growth factor by regulating the signaling events in BMP pathway. Cell Tissue Res 361: 723-731, 2015.
15. Zhou Y, Zhang Q, Gao Y, Tan M, Zheng R, Zhao L and Zhang X: Induced pluripotent stem cell-conditioned medium suppresses pulmonary fibroblast-to-myofibroblast differentiation via the inhibition of TGF- $\beta 1 /$ Smad pathway. Int J Mol Med 41: 473-484, 2018.

16. Zhou X, Tao Y, Liang C, Zhang Y, Li H and Chen Q: BMP3 alone and together with TGF- $\beta$ Promote the differentiation of human mesenchymal stem cells into a Nucleus Pulposus-Like Phenotype. Int J Mol Sci 16: 20344-20359, 2015.

17. Cannon B and Nedergaard J: Cell biology: Neither brown nor white. Nature 488: 286-287, 2012.

18. Moon MY, Kim HJ, Kim MJ, Uhm S, Park JW, Suk KT, Park JB, Kim DJ and Kim SE: Rap1 regulates hepatic stellate cell migration through the modulation of RhoA activity in response to TGF- 31 . Int J Mol Med 44: 491-502, 2019.

19. Tu WZ, Fu YB and Xie X: RepSox, a small molecule inhibitor of the TGF $\beta$ receptor, induces brown adipogenesis and browning of white adipocytes. Acta Pharmacol Sin 40: 1523-1531, 2019

20. Li X, Guo Y, Yao Y, Hua J, Ma Y, Liu C and Guan W: Reversine increases the plasticity of long-term cryopreserved fibroblasts to multipotent progenitor cells through activation of Oct4. Int J Biol Sci 12: 53-62, 2016.

21. Ma C, Guo Y, Wen H, Zheng Y, Tan L, Li X, Wang C, Guan W and Liu C: Identification and multilineage potential research of a novel type of Adipose-Derived mesenchymal stem cells from goose inguinal groove. DNA Cell Biol 37: 731-741, 2018.

22. Waldsee R, Eftekhari S, Ahnstedt H, Johnson LE and Edvinsson L: CaMKII and MEK1/2 inhibition time-dependently modify inflammatory signaling in rat cerebral arteries during organ culture. J Neuroinflammation 11: 90, 2014.

23. Wang M, Zhang G, Wang Y, Liu T, Zhang Y, An Y and Li Y: Crosstalk of mesenchymal stem cells and macrophages promotes cardiac muscle repair. Int J Biochem Cell Biol 58: 53-61, 2015.

24. Trapnell C, Pachter L and Salzberg SL: TopHat: Discovering splice junctions with RNA-Seq. Bioinformatics 25: 1105-1111, 2009.

25. Anders S and Huber W: Differential expression analysis for sequence count data. Genome Biol 11: R106, 2010.

26. Yu G, Wang LG, Han Y and He QY: ClusterProfiler: An R package for comparing biological themes among gene clusters. OMICS 16: 284-287, 2012.

27. Li W, Wang P, Zhang B, Zhang J, Ming J, Xie W and Na J: Differential regulation of $\mathrm{H} 3 \mathrm{~S} 10$ phosphorylation, mitosis progression and cell fate by Aurora Kinase B and C in mouse preimplantation embryos. Protein Cell 8: 662-674, 2017.

28. Sotero-Caio CG, de Souza MJ, Cabral-de-Mello DC, Brasileiro-Vidal AC and Guerra M: Phosphorylation of histone H3S10 in animal chromosomes: Is there a uniform pattern? Cytogenet Genome Res 135: 111-117, 2011.

29. Linhart HG, Ishimura-Oka K, DeMayo F, Kibe T, Repka D, Poindexter $\mathrm{B}$, Bick RJ and Darlington GJ: C/EBPalpha is required for differentiation of white, but not brown, adipose tissue. Proc Natl Acad Sci USA 98: 12532-12537, 2001.

30. Mei L, Sang W, Chen Z, Zheng L, Jin K, Lou C, Huang W and He D: Small molecule inhibitor RepSox prevented ovariectomy-induced osteoporosis by suppressing osteoclast differentiation and bone resorption. J Cell Physiol 233: 9724-9738, 2018.

31. Li Q and Huang Q: Single-cell qPCR demonstrates that Repsox treatment changes cell fate from endoderm to neuroectoderm and disrupts epithelial-mesenchymal transition. PLoS One 14: e0223724, 2019.

32. Zhao B, Guan H, Liu JQ, Zheng Z, Zhou Q, Zhang J, Su LL and Hu DH: Hypoxia drives the transition of human dermal fibroblasts to a myofibroblast-like phenotype via the TGF-beta1/Smad3 pathway. Int J Mol Med 39: 153-159, 2017.

33. Guo M, Zhou JJ and Huang W: Metformin alleviates endometrial hyperplasia through the UCA1/miR144/TGF $\beta 1 / \mathrm{AKT}$ signaling pathway. Int J Mol Med 45: 623-633, 2020.

34. Han S, Cui C, Wang Y, He H, Liu Z, Shen X, Chen Y, Li D, Zhu Q and Yin H: Knockdown of CSRP3 inhibits differentiation of chicken satellite cells by promoting TGF- $\beta / \mathrm{Smad} 3$ signaling. Gene 707: 36-43, 2019.

35. Wen X, Liu Y, Bai Y, Li M, Fu Q and Zheng Y: LOXL2, a copper-dependent monoamine oxidase, activates lung fibroblasts through the TGF- $\beta /$ Smad pathway. Int J Mol Med 42: 3530-3541, 2018 . 
36. Chen J, Liu J, Yang J, Chen Y, Chen J, Ni S, Song H, Zeng L, Ding K and Pei D: BMPs functionally replace Klf4 and support efficient reprogramming of mouse fibroblasts by Oct 4 alone. Cell Res 21: 205-212, 2011.

37. Wu L, Cai X, Zhang S, Karperien M and Lin Y: Regeneration of articular cartilage by adipose tissue derived mesenchymal stem cells: Perspectives from stem cell biology and molecular medicine. J Cell Physiol 228: 938-944, 2013.

38. Zhang Y, Fan K, Xu X and Wang A: The TGF- $\beta 1$ Induces the Endothelial-to-Mesenchymal Transition via the UCA1/miR-455/ZEB1 Regulatory axis in human umbilical vein endothelial cells. DNA Cell Biol 39: 1264-1273, 2020.
39. Zhu YC, Wang YK, Bai SJ, Zha FF, Feng G, Gao CP and Liu J: Suppression of CIP4/Par6 attenuates TGF- $\beta 1$-induced epithelial-mesenchymal transition in NRK-52E cells. Int J Mol Med 40: 1165-1171, 2017.

This work is licensed under a Creative Commons Attribution-NonCommercial-NoDerivatives 4.0 International (CC BY-NC-ND 4.0) License. 